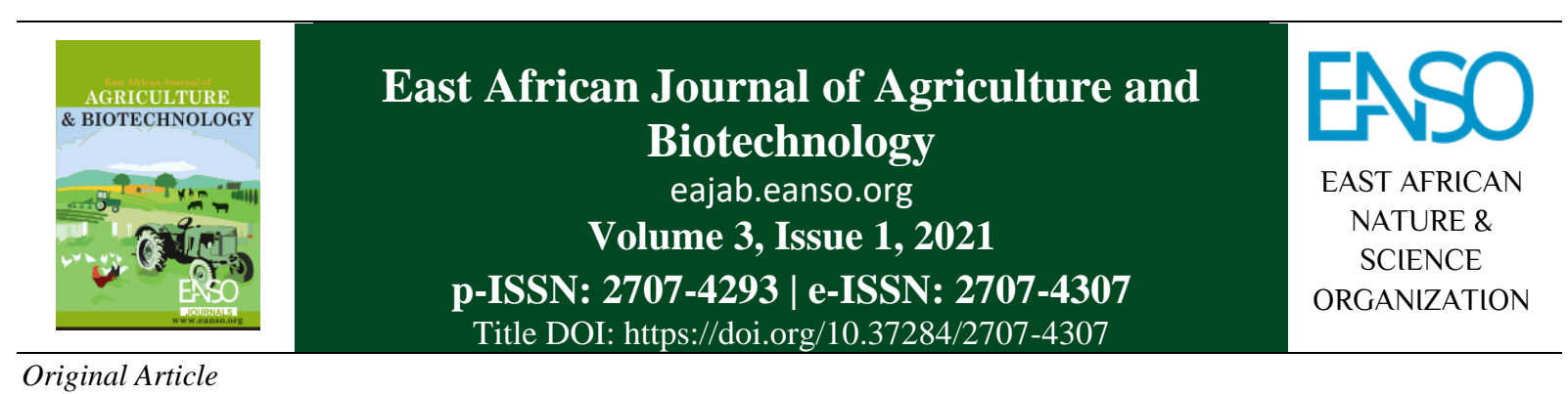

\title{
Effect of Production Management Skills on the Production Level of ESP Financed Aquaculture Farms in Kisumu West Constituency, Kenya
}

\author{
James Owek Ochieng, ${ }^{1}$ Ochieng' Marilyn Ahonobadha ${ }^{1}$ \& George Mark Onyango ${ }^{1}$ \\ ${ }^{1}$ Maseno University, P. O. Box 333, Maseno, Kenya. \\ ORCID ID: https://orcid.org/0000-0003-2395-7609; Correspondent, Email: ahonobadha79@gmail.com
}

Article DOI: https://doi.org/10.37284/eajab.3.1.341

Date Published: ABSTRACT

10 June 2021 The Kenyan Economic Stimulus Program was developed with an objective to spur regional development. The program targeted the establishment of 200 fish ponds in the selected constituencies in Kenya. Farmers were trained on

Keywords: production management skills and capacity building by the department of fisheries and other institutions sharing similar objectives. In spite of this

Farmer intervention, there has been a declining trend in the production of fish in

Management Skills, Aquaculture farms,

Economic Stimulus

Program Kisumu West Constituency. This study therefore sought to establish if a significant relationship existed between the decline in the performance of aquaculture farms and acquisition of production management skills. The main objective of the study was to establish the effect of farmer production management skills on production levels of the Economic Stimulus Program financed aquaculture farming projects in Kisumu West Constituency, Kisumu County, Kenya. A total of 389 farmers were interviewed. The population of 417 farmers consisted of farmers with different forms of financing including economic stimulus, personal, and Sacco/group loans. A descriptive survey design was employed to collect both quantitative and qualitative data to achieve the objective of the study. Data was collected using guided interview schedules, key informant interviews, observation, and the use of periodicals, publications, and journals for secondary data. Data was summarised using pivot tables analysed using thematic analysis, percentages, mean, frequency distribution, chi-square and Pearson's correlation coefficient between the variables. The data was then presented using text, tables and graphs. It was established that capacity building and training on technical and post-harvest management skills was not effectively done by the extension officers at the initiation stage of the projects and subsequently during the project implementation. This led to a decline in the performance of farms and a high dropout rate of farmers. As a result, the objective of ESP as far as commercialisation of aquaculture farms was not achieved. The study

$9 \mid$ This work is licensed under a Creative Commons Attribution 4.0 International License. 
recommends the development of aquaculture best production management practice and integrated farmer training program across the Constituency.

\section{APA CITATION}

Ochieng, J. O., Ahonobadha, O. M., \& Onyango, G. M. (2021). Effect of Production Management Skills on the Production Level of ESP Financed Aquaculture Farms in Kisumu West Constituency, Kenya. East African Journal of Agriculture and Biotechnology, 3(1), 9-23. https://doi.org/10.37284/eajab.3.1.341

\section{CHICAGO CITATION}

Ochieng, James Owek., Ochieng' Marilyn Ahonobadha., and George Mark Onyango. 2021. "Effect of Production Management Skills on the Production Level of ESP Financed Aquaculture Farms in Kisumu West Constituency, Kenya". East African Journal of Agriculture and Biotechnology 3 (1), 9-23. https://doi.org/10.37284/eajab.3.1.341.

\section{HARVARD CITATION}

Ochieng, J. O. Ahonobadha, O. M. Onyango, G. M. (2021) "Effect of Production Management Skills on the Production Level of ESP Financed Aquaculture Farms in Kisumu West Constituency, Kenya", East African Journal of Agriculture and Biotechnology, 3(1), pp. 9-23. doi: 10.37284/eajab.3.1.341.

\section{IEEE CITATION}

J. O. Ochieng, O. M. Ahonobadha G. M. Onyango. "Effect of Production Management Skills on the Production Level of ESP Financed Aquaculture Farms in Kisumu West Constituency, Kenya", EAJAB, vol. 3, no. 1, pp. 9-23, Jun. 2021.

\section{MLA CITATION}

Ochieng, James Owek., Ochieng' Marilyn Ahonobadha., and George Mark Onyango. "Effect of Production Management Skills on the Production Level of ESP Financed Aquaculture Farms in Kisumu West Constituency, Kenya". East African Journal of Agriculture and Biotechnology, Vol. 3, no. 1, Jun. 2021, pp. 9-23, doi:10.37284/eajab.3.1.341.

\section{NTRODUCTION}

A sustainable business enterprise requires adequate capital to meet the operational expenses before returns are realised. Aquaculture farming in Kenya has undergone significant development over time. In relation to the development of the enterprise in the world, fish culture has proved successful in improving the standards of living of rural farmers in Asia, where fish culture has a long tradition (Mwatsuma, Cherutich \& Nyamu, 2012; Edwards, 2002).

FAO (2018) global aquaculture production (including aquatic plants) in 2016 was 110.2 million tons with the first sale value estimated at USD 243.5 billion, of which 80.0 million tons were food fish (USD 231.6 billion). This accounted for 5.8\% growth during the period 2001 - 2016. Earthen ponds remain the most commonly used type of facility in inland aquaculture production. In 2016, inland aquaculture was the source of 52.4 million tons of food fish or $64.2 \%$ of the world's farmed food fish production. According to Muir and Allison (2007), globally, aquaculture has expanded at an average annual rate of $8.9 \%$ since 1970 , making it the fastestgrowing food production sector.

Aquaculture produces around half of the fish for human consumption and must continue to grow because limited capture fisheries will be unable to meet demand from a growing population. Aquaculture production is rising rapidly and by 2030 is estimated that aquaculture production will be close to that of capture production (Brandler, 2007). This is against the backdrop that many inland fisheries are threatened by climate change that has direct effects through reduced precipitation and greater evaporation and indirect effects when more water is used for irrigation Muir and Allison (2007) through loss of cultured stock, increased production costs due to low water quality and availability for aquaculture during droughts. These impacts are likely to be felt most strongly by the poorest aquaculture farmers, whose typically small ponds retain less water and dry up faster.

Although aquaculture continues to be the world's fastest-growing and diverse food production sector, the production of fish within the developing countries is highly dependent upon the local manufacture of aquaculture feeds composed of mainly imported feed ingredient sources. It therefore follows that future aquaculture feed industry and government efforts should be focused on the increased use of locally available non-food grade feed resources (FAO, 2018).

A new wave of optimism has equally been observed with several privately funded tilapia

10 This work is licensed under a Creative Commons Attribution 4.0 International License. 
farming projects showing promise. These include Kafue fish farms in Zambia, Lake Harvest in Zimbabwe and several farms in Ghana, Nigeria and Malawi (FAO, 2012). In Egypt, pond-based aquaculture of tilapia was highly profitable which resulted in private sector investment and total aquaculture production grew from only 19 thousand tons per year in 1980 to 340 thousand tons per year in 2000 , reaching an estimated total of 1.137 million tons per year in 2014. Aquaculture represented $77 \%$ of total Egyptian fish production in 2014 compared to only $54 \%$ in 2004 (Dickson et al., 2016).

In Kenya, aquaculture farming was identified as one of the key sectors that could lead to the growth of the economy after the 2007/2008 post-election violence. During Economic Stimulus Program (ESP), earthen ponds were constructed in most parts of the country after mapping areas that were suitable for aquaculture. Despite the gain in the growth of the number of ponds aquaculture production in Kenya reduced from 24,096 tons in 2014 to 18,656 tons in 2015 and a further 14,952 tons in 2016. The number of operational fish ponds reduced from 69,194 (2013) to 60,277 in 2015 (Opiyo et al., 2018).

\section{METHODOLOGY}

During the study, a descriptive research design was used. According to Bhattacherjee (2012), descriptive research is directed towards making careful observations and detailed documentation of a phenomenon of interest. The survey focused on farmers who were engaged in aquaculture in Kisumu West Constituency. The farmers who were not actively engaged in aquaculture formed an integral part of the study in getting the perspective of why certain farmers pull out of the ESP, if there are management challenges and provide a benchmark against which the active farmers can be assessed.

The design then used collected data based on the source of finance for the project (ESP, personal, and/or Sacco/group) to assess parameters in farmer technical skills in fish farming. Comparisons were derived on the level of attainment of the requisite skills and performance of the farms depending on the source of funds. Farmer interview, observation and key informant interviews were used to collect data. The data collected was both qualitative and quantitative in nature. The collected data was such that they could reliably and validly address the specific objectives of the study. The collected data were coded to enable data analysis for both quantitative and qualitative data. The qualitative data was analysed to present patterns, themes and categories. Relationships between the variables were determined using frequency percentages, Chi-square and cross-tabulation.

\section{Area of Study}

Kisumu West Constituency was formed from Kisumu Town West and Kisumu Rural Constituencies. Kisumu West Constituency is strategically located and borders Kisumu Central Constituency to the South East, Kisumu East Constituency to the East and North East, Seme Constituency to the West, Vihiga County to the North and Lake Victoria to the South. The Constituency has an estimated population of 131,246 residents with an estimated area of 358.7 square Kilometres. It has five wards, namely Central Kisumu, North West Kisumu, West Kisumu, South West Kisumu and North Kisumu. Though cosmopolitan, the main spoken languages are Dholuo, Kiswahili and English.

The topography is undulating with seasonal streams meandering through the plain land and hills towards Lake Victoria. The major economic activities in the area include small, medium and micro business enterprises, subsistence agriculture, livestock farming and commercial residential housing. Figure 1 shows the position of Kisumu West Constituency. 


\section{Figure 1: Kisumu West Constituency}

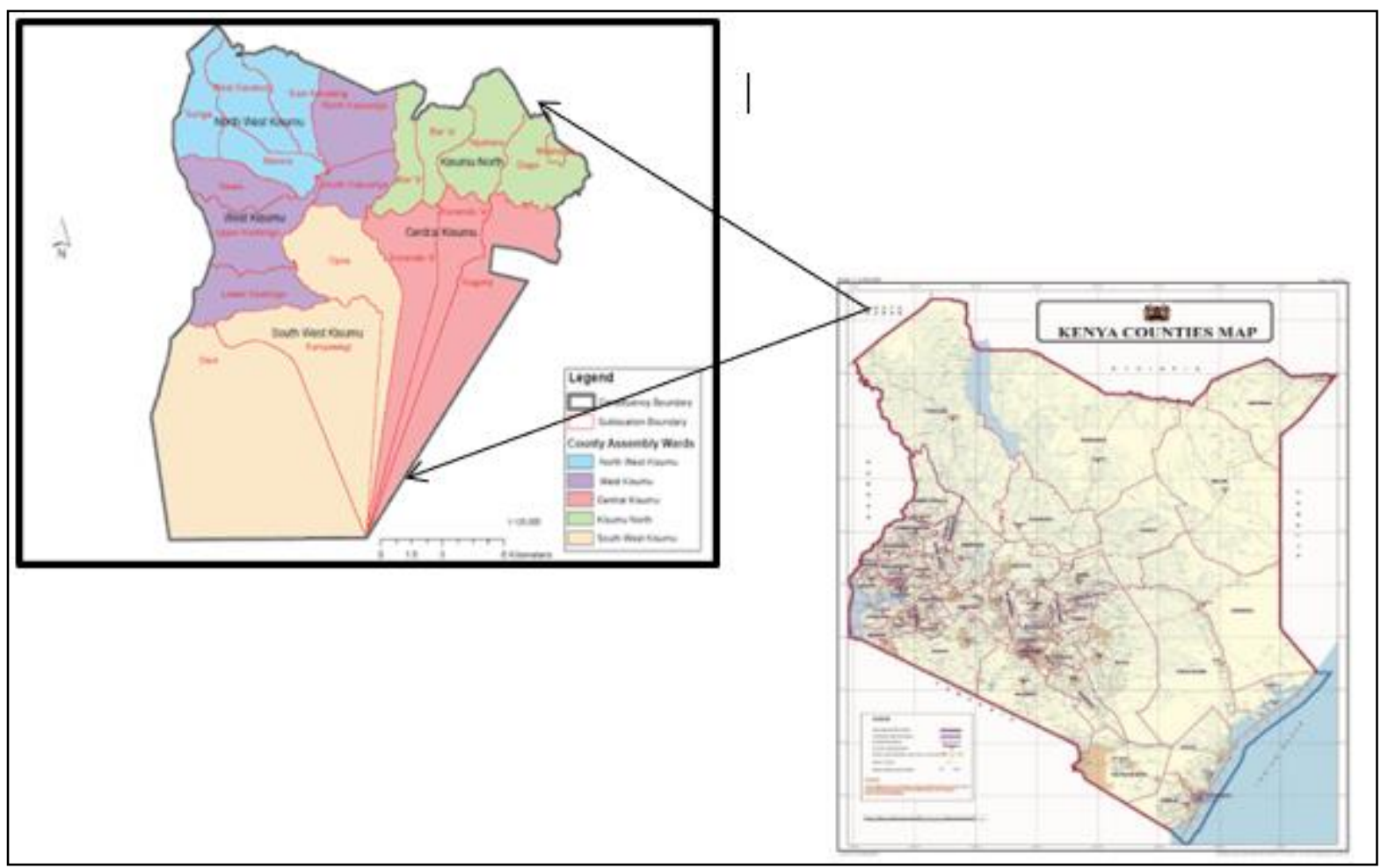

\section{Population of Study}

From the Kisumu West Sub-County Fisheries Department Office, the total number of listed aquaculture farmers were 417 , despite the fact that they are not categorised based on the source of finance. The majority of the fish farms are individual-owned, although some are managed by groups, schools, universities and Government agricultural institutions. During the study, a total of 389 farmers were interviewed with the numbers categorised as per Table 1 below.

\section{Table 1: Categorization of Farmers}

\begin{tabular}{ll}
\hline Source of funds & No. of farmers \\
\hline ESP & 156 \\
Personal & 124 \\
ESP and Personal & 58 \\
Sacco/Group & 43 \\
Personal and Sacco/Group & 8 \\
TOTAL & 389 \\
\hline
\end{tabular}

\section{RESULTS AND DISCUSSIONS}

This section provides an analysis of the production level of the farms within the Kisumu West constituency. The findings should be able to assist evaluate if the program achieved its intention of commercialising aquaculture by increasing the productivity level of fish harvested per pond and improve the economic status of the farmer and the country at large.

\section{Source of capital}

The Kenyan government through ESP provided financial support to identified farmers to develop commercialised aquaculture farms. The information gathered from the respondents is represented in Figure 2 shown below. 


\section{Figure 2: Pie Chart showing source of capital for the aquaculture project}

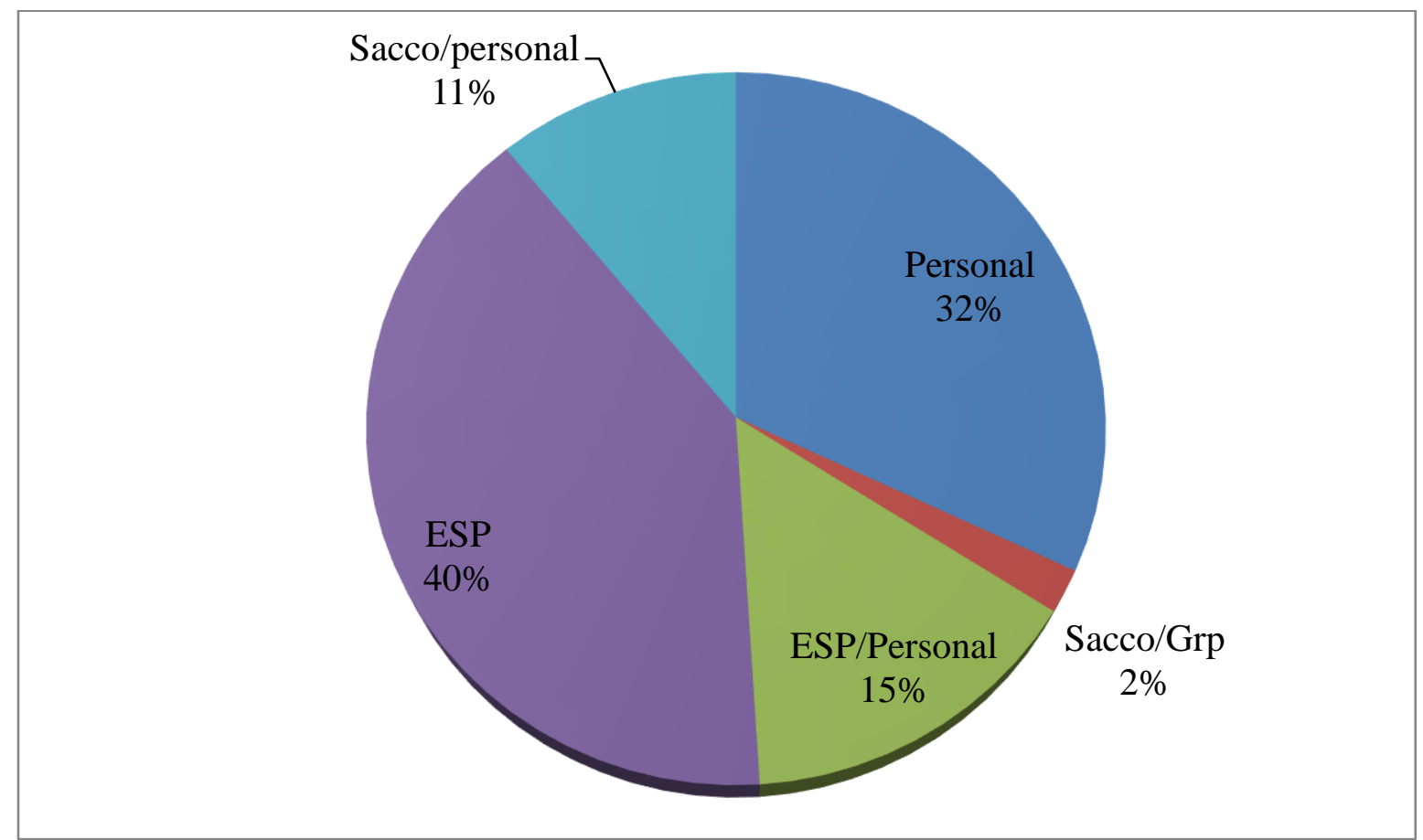

From Figure 2, it can be deduced that of the respondents interviewed, $40 \%$ of the farms were financed from the ESP kitty, 32\% established the projects from personal finances, $15 \%$ used both personal and ESP funds, $11 \%$ received their funding from Group/Sacco loans while $2 \%$ of those interviewed used had both personal and Sacco/Group loan as a source of funds to establish the projects. This indicates that a greater percentage of the farms received funding from the government to establish their farms. The mainstream financial institutions including banks and microfinance institutions did not finance any aquaculture project within the Constituency.
Respondents from the fisheries department said that ESP was earmarked to fully finance the farmers until harvesting of fish. However, from the farm respondents, some farms did not receive other forms of financing leading to drop out. Some farms received partial funding but based on the farmer's personal fascination in the initiative and access to alternative sources of finance including formal employment, continued with the projects. Table 2 below shows the forms of financing received from the government on the established aquaculture farms. 
Table 2: Forms of financing for the aquaculture projects

\begin{tabular}{|c|c|c|c|c|c|c|c|c|c|c|}
\hline \multicolumn{11}{|c|}{ Form of Finance } \\
\hline $\begin{array}{l}\text { Source } \\
\text { of fund }\end{array}$ & $\begin{array}{l}\text { Pond } \\
\text { construction }\end{array}$ & $\begin{array}{l}\text { Pond } \\
\text { construction, } \\
\text { Feeds } \\
\text { purchase, } \\
\text { Fertiliser, } \\
\text { Training, } \\
\text { Fingerlings }\end{array}$ & $\begin{array}{l}\text { Pond } \\
\text { construction, } \\
\text { Feeds } \\
\text { purchase, } \\
\text { training, } \\
\text { Fingerlings }\end{array}$ & $\begin{array}{l}\text { Pond } \\
\text { construction, } \\
\text { Feeds } \\
\text { purchase, } \\
\text { Fingerlings, } \\
\text { Pond liner. }\end{array}$ & $\begin{array}{l}\text { Pond } \\
\text { construction, } \\
\text { Feeds } \\
\text { purchase, } \\
\text { Fingerlings }\end{array}$ & $\begin{array}{l}\text { Pond } \\
\text { construction, } \\
\text { Feeds } \\
\text { purchase, } \\
\text { Fingerlings, } \\
\text { Pond liner. }\end{array}$ & $\begin{array}{l}\text { Pond } \\
\text { construction, } \\
\text { Training, } \\
\text { Fingerlings. }\end{array}$ & $\begin{array}{l}\text { Pond } \\
\text { construction, } \\
\text { Fingerlings } \\
\text { and Pond } \\
\text { Liner. }\end{array}$ & $\begin{array}{l}\text { Feeds } \\
\text { purchase, } \\
\text { Training, } \\
\text { and } \\
\text { Fingerlings. }\end{array}$ & Total \\
\hline ESP & 4 & 7 & 87 & 23 & 14 & 6 & 2 & 14 & & 157 \\
\hline $\begin{array}{l}\text { ESP \& } \\
\text { Personal }\end{array}$ & 0 & 0 & 38 & 9 & 7 & 0 & 0 & 0 & & 56 \\
\hline Total & 4 & 7 & 125 & 32 & 21 & 6 & 2 & 14 & & 213 \\
\hline
\end{tabular}


The department of fisheries in Kisumu West Sub County stated that funding for projects by ESP was done based on different categories that included pond construction, purchase of pond liners for areas with low water retention soils, purchase of 1,000 fingerlings to stock each pond, provision of feeds for the entire production cycle and training of the farmers on the production management skills.

Table 2 shows the different combinations of forms of finance received from ESP. From the farm interviews carried out, of the 389 farmers, 157 ponds received full funding for some components of the aquaculture project. Four ponds received funds towards the construction of the ponds without any

\section{Figure 3: Pond not fully covered by a pond liner}

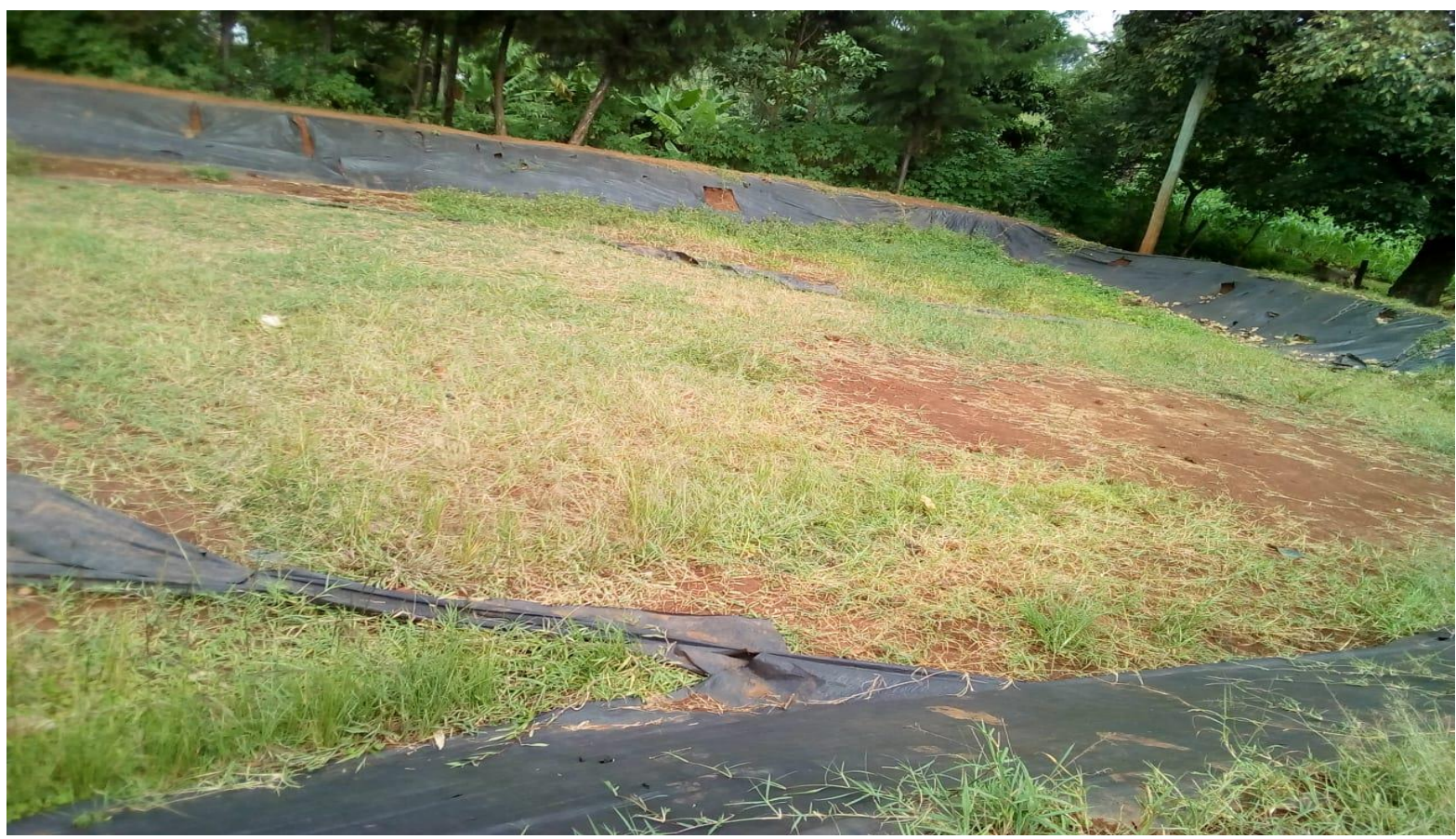

The owner of the pond in Figure 3 was funded by ESP but could not retain water since the pond liner provided to the farmer was not sufficient for the pond leading to farmer drop out.

According to FAO (2012), one of the major constraints affecting aquaculture farming in African countries is the lack of capital. The lack of capital by the rural-based farmers was to be addressed through the inception of ESP. In the first phase of ESP in the 2009/2010 financial year, 200 fish ponds were constructed in each of the 140 constituencies, additional funding and therefore were not operationalised. Seven ponds received full establishment funding without the pond liner since the soil type was assumed suitable for use; 87 ponds were fully funded plus the pond liner but lacked fertiliser which is a key component in production. It is clear that most of the farms funded missed out on the fertiliser component. For those who received fertilisers against an expectation of $15 \mathrm{~kg}$, only a measure of $2 \mathrm{Kg}$ tin was issued to the farmer. It is also evident that fertiliser though a key ingredient during the growth of the fingerlings and production in total, was never distributed to most of the farmers. Figure 3 below shows a pond within the Kisumu West constituency. 
ponds was due to the fact that, Kisumu West constituency was formed during the electoral boundary review and was hived off from Kisumu Rural and Kisumu Town constituencies that received the funds for the projects. However, no sufficient explanation was given on the variation in the amount of fertiliser issued to the farmers.

In total, 213 farms were either funded partially or received full finance of all or some components of areas financed. The training component of ESP was aimed at inculcating pond management skills to the farmers and from the data collected, only 168 farmers directly benefited from the program on that parameter.

\section{Current Status of Farm Activity}

Table 3 below provides a summary of the findings of the current status of the farms if active or inactive and level of production. The inactive farms are dropout farmers.

Table 3: The source of capital and current status of the farm.

\begin{tabular}{|c|c|c|c|c|c|c|}
\hline Source of Funds & Active & Inactive & $\begin{array}{l}\text { Ponds } \\
\text { Harvested }\end{array}$ & Pieces & Weight & $\begin{array}{lr}\text { No. of } \\
\text { Employees }\end{array}$ \\
\hline $\mathrm{ESP}$ & 31 & 126 & 34 & 10040 & 1318 & 143 \\
\hline PERSONAL & 89 & 37 & 25 & 20840 & 1530 & 156 \\
\hline SACCO/GRP & 35 & 9 & 5 & 2100 & 290 & 35 \\
\hline ESP \& PERSONAL & 28 & 28 & 11 & 4830 & 955 & 27 \\
\hline PERSONAL, SACCO/GRP & 4 & 2 & 1 & 160 & 200 & 4 \\
\hline TOTAL & 187 & 202 & 76 & 37970 & 4293 & 365 \\
\hline
\end{tabular}

From Table 3, 48.07\% of the farms in Kisumu West Constituency are actively in production against $51.93 \%$ that are not active. Of the active farms, $16.6 \%$ were financed through ESP, about half financed through proprietor personal finance, 18.7 $\%$ financed through loans from a group or Sacco, $15.0 \%$ financed through both ESP and personal funds and $2.1 \%$ funded through personal and Sacco/Group finance. This shows that a third of the firms received funding either partially or fully from the ESP kitty.

For the farms that are not active, $62.4 \%$ were financed by ESP, and $18.3 \%$ financed through entrepreneurs' personal finances, $4.5 \%$ financed through loans from a group or Sacco, $13.9 \%$ financed through both ESP and personal funds and $1.0 \%$ funded through personal and Sacco/Group finance. Taking a comparison of the performance of the farms funded by ESP and personal finance, it was noted that a great number of drop out farmers ha finance from ESP which was 126 farms out of 187. Of the 34 ponds harvested that were funded by ESP, 10,040 pieces of fish were harvested. Personal financed farms with the same size harvested 20,840 pieces which is double the number of fish harvested. ESP-funded active farms are 31 and the ponds harvested in the last year stand at 34; this showed that the farmers are continually dropping out from the enterprise upon harvesting. From the findings, it can be concluded that farms that were financed through the personal finances of the entrepreneur were better managed compared to those funded through ESP. The study results are in line with that of Dickson et al. (2016) that pond-based farming is a highly profitable venture in Egypt, is widely managed and funded through private sector investment. The results also corroborate with the development of aquaculture farms in Zambia, Ghana and Malawi as reported by FAO (2012). Figure 4 shows a picture of a well-managed pond. 


\section{Figure 4: A well-managed pond funded through personal finance}

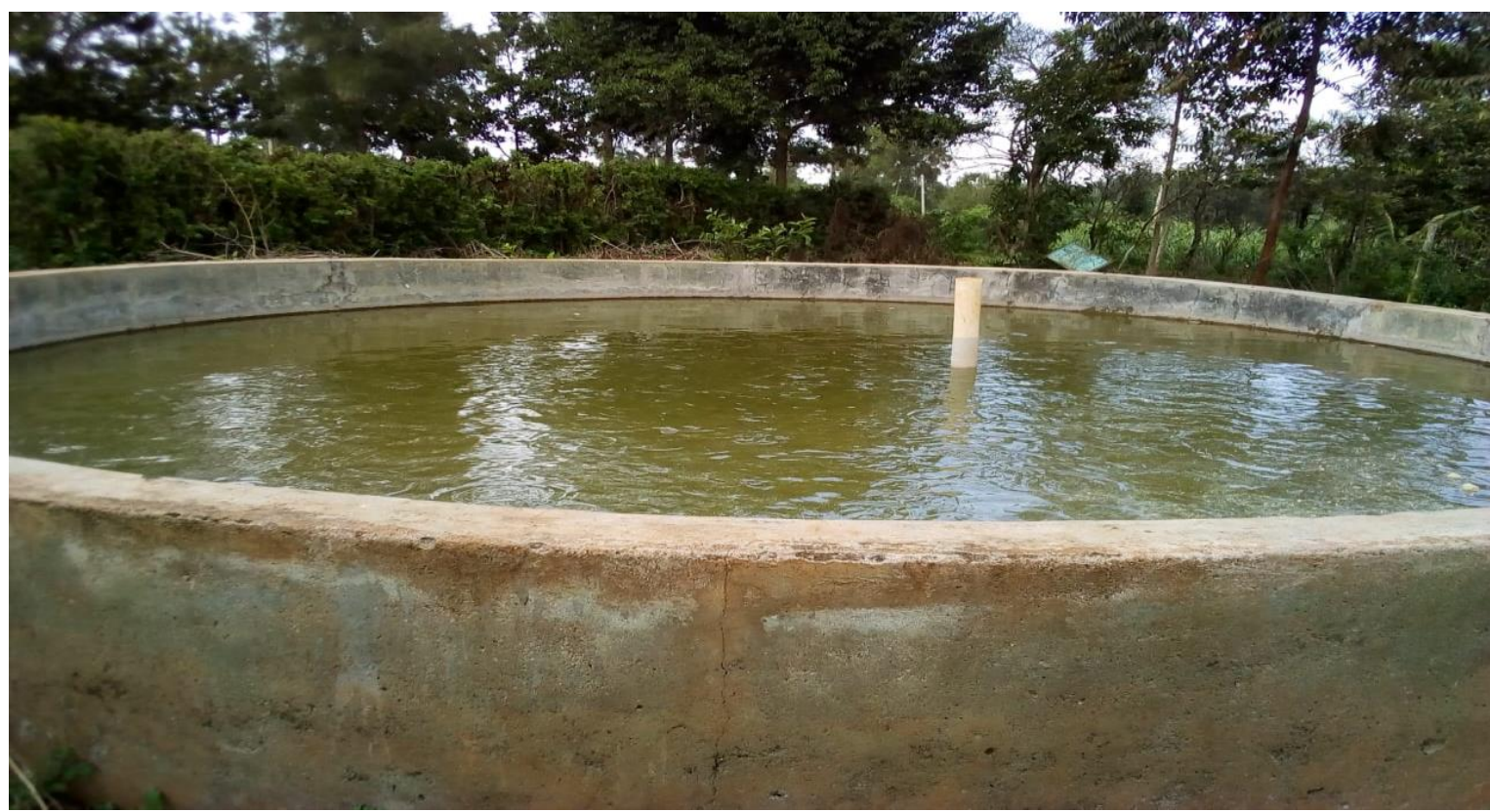

Figure 4 shows an example of a pond belonging to a committed farmer with an established farm in the North West Kisumu Ward in the Kisumu West constituency. The farm was established with the farmers' own resources, and its level of production has been optimally resulting in income earnings to the farmer. This farmer was, however, not a recipient of ESP. Figure 5 shows a picture of a pond whose owner was a recipient of ESP.

\section{Figure 5: Set of ponds funded through ESP}

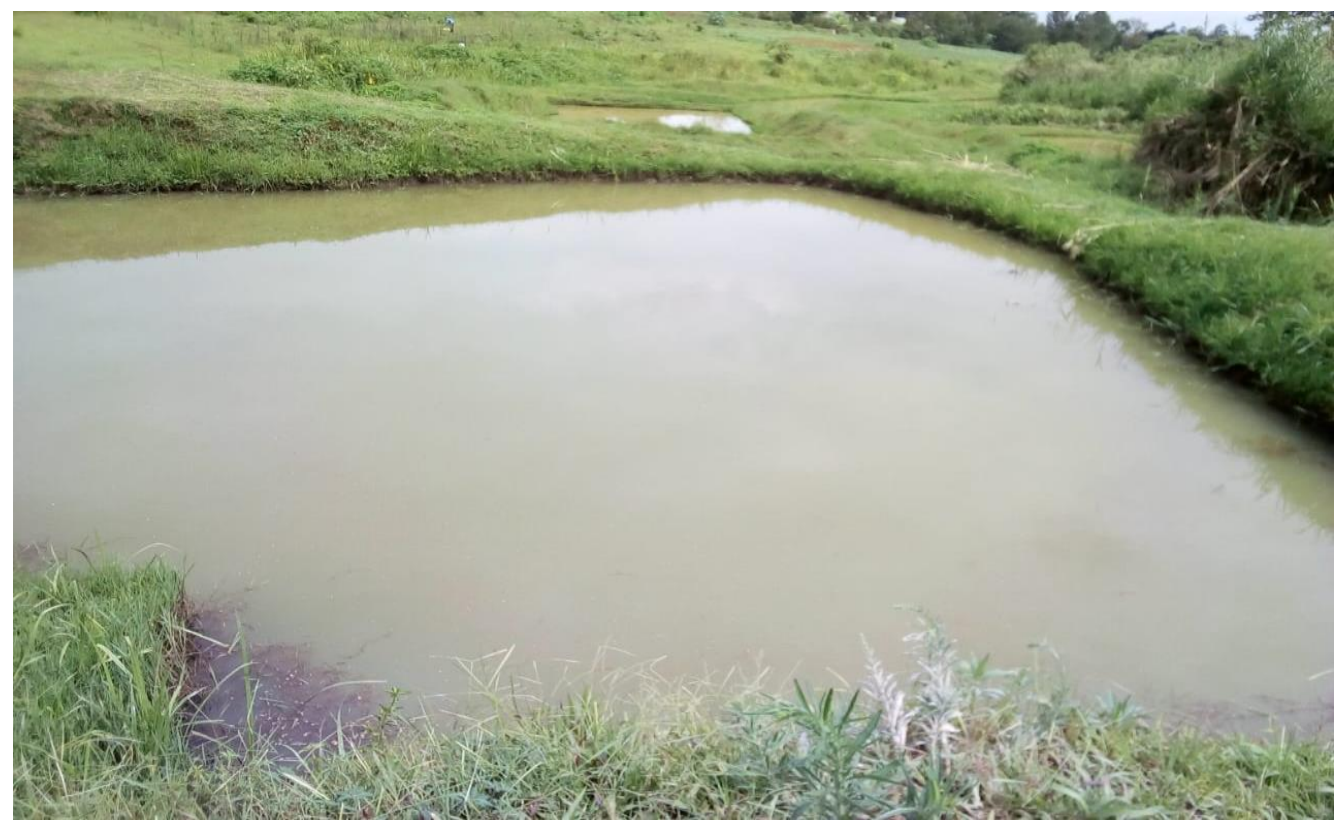

Figure 5 shows a farm whose owner received funding through ESP. From the farmer interview, it was established that he has since grown the enterprise to own three ponds. The farmer received funding for Pond construction, feeds purchase, fertiliser, training and purchase of 1,000 fingerlings.

17 | This work is licensed under a Creative Commons Attribution 4.0 International License. 
From the income earned in addition to personal finances, the farmer has been able to increase the number of ponds at the farm to three.
Table 4 provides a detailed analysis of the farms.

Table 4: Detailed analysis of the farms

\begin{tabular}{llllll}
\hline Variable & Observations & Mean & Std. Dev. & Min & Max \\
\hline Active & 5 & 37.4 & $\mathbf{3 1 . 2 7 7 7 9}$ & $\mathbf{4}$ & $\mathbf{8 9}$ \\
Inactive & 5 & 40.4 & $\mathbf{4 9 . 8 8 2 8 6}$ & $\mathbf{2}$ & $\mathbf{1 2 6}$ \\
Ponds Harvested & 5 & 15.2 & $\mathbf{1 3 . 8 9 9 6 4}$ & $\mathbf{1}$ & $\mathbf{3 4}$ \\
No. Of Pieces & 5 & $\mathbf{7 5 9 4}$ & $\mathbf{8 2 8 4 . 4 3 6}$ & $\mathbf{1 6 0}$ & $\mathbf{2 0 8 4 0}$ \\
Weight & 5 & $\mathbf{8 5 8 . 6}$ & $\mathbf{5 9 7 . 5 3 2 3}$ & $\mathbf{2 0 0}$ & $\mathbf{1 5 3 0}$ \\
Employee & 5 & $\mathbf{7 3}$ & $\mathbf{7 0 . 9 0 4 8 7}$ & $\mathbf{4}$ & $\mathbf{1 5 6}$ \\
\hline
\end{tabular}

Table 4 shows the active farms have a mean of 37.4 farms standard deviation of 31.28 depending on the sources of funds and positively skewed by 0.9045 from the normal curve. The inactive farms on the other hand, have a mean of 40.4 a standard deviation of 49.88 and positively skewed by 1.21081 from the normal curve. This shows that more farms are inactive. Inactive farms show a wide deviation from the mean value across the different modes of funding, that is a minimum of 2 dropout farmers to a maximum of 126 farmers. Table 5 shows a breakdown of the type of fish in the ponds and a breakdown of the harvest. Table 6 gives a sum of the weights harvested.

Table 5: Type of fish farmed and the count of ponds harvested.

\begin{tabular}{|c|c|c|c|c|c|c|}
\hline \multirow[b]{2}{*}{ Source of Funds } & \multicolumn{6}{|c|}{ Fish Type } \\
\hline & Catfish & Other & Tilapia & Tilapia Catfish & Tilapia other & Total \\
\hline ESP & 0 & 0 & 29 & 5 & 0 & 34 \\
\hline PERSONAL & 1 & 1 & 19 & 3 & 1 & 25 \\
\hline SACCO/GROUP & 0 & 1 & 4 & 0 & 0 & 5 \\
\hline ESP PERSONAL & 0 & 0 & 5 & 5 & 1 & 11 \\
\hline PERSONAL, SACCO/GROUP & 0 & 0 & 0 & 1 & 0 & 1 \\
\hline Grand Total & 1 & 2 & 57 & 14 & 2 & 76 \\
\hline
\end{tabular}

Table 6: Type of fish and the sum of the weight of fish harvested

\begin{tabular}{lllllll}
\hline Sum of weight harvested & \multicolumn{2}{l}{ Fish type } & & & & \\
\hline Source of funds & $\begin{array}{l}\text { Catfis } \\
\text { h }\end{array}$ & $\begin{array}{l}\text { Othe } \\
\text { r }\end{array}$ & $\begin{array}{l}\text { Tilapi } \\
\text { a }\end{array}$ & $\begin{array}{l}\text { Tilapia } \\
\text { Catfish }\end{array}$ & $\begin{array}{l}\text { Tilapia } \\
\text { other }\end{array}$ & $\begin{array}{l}\text { Tota } \\
\text { l }\end{array}$ \\
\hline ESP & 0 & 0 & 1194 & 124 & 0 & 1318 \\
PERSONAL & 0 & 14 & 1401 & 96 & 20 & 1531 \\
SACCO/GROUP & 0 & 75 & 215 & 0 & 0 & 290 \\
ESP PERSONAL & 0 & 0 & 650 & 55 & 250 & 955 \\
PERSONAL, & 0 & 0 & 0 & 200 & 0 & 200 \\
SACCO/GROUP & & & & & & \\
\hline Total & $\mathbf{0}$ & $\mathbf{8 9}$ & $\mathbf{3 4 6 0}$ & $\mathbf{4 7 5}$ & $\mathbf{2 7 0}$ & $\mathbf{4 2 9 4}$ \\
Percentage & $\mathbf{0}$ & $\mathbf{2 . 0 7}$ & $\mathbf{8 0 . 5 8}$ & $\mathbf{1 1 . 0 6}$ & $\mathbf{6 . 2 9}$ & $\mathbf{1 0 0}$ \\
Average weight per pond & $\mathbf{0}$ & $\mathbf{4 4 . 5}$ & $\mathbf{6 0 . 7}$ & $\mathbf{3 3 . 9}$ & $\mathbf{1 3 5}$ & $\mathbf{5 6 . 5}$ \\
\hline
\end{tabular}

From the 76 ponds harvested, a total of $4,294 \mathrm{Kg}$ of fish was harvested, which shows an average of 56.5 $\mathrm{Kg}$ per pond. It was noted that one pond stocked with catfish had no fish to be harvested, a clear indication of the effects of fish predation and theft.

18 This work is licensed under a Creative Commons Attribution 4.0 International License. 
Farms financed by ESP and personal funds exemplified the highest estimated weight harvested at $1,318 \mathrm{Kg}$ and $1,531 \mathrm{Kg}$, respectively, even though ESP farms had the highest number of ponds harvested over a period of one year. Data provided by the Department of Fisheries, Kisumu West Subcounty during the interview showed that in the financial year $2016-2017,2,319 \mathrm{Kg}$ of fish was harvested from 47 ponds with an average of 49.34
$\mathrm{Kg}$ per pond. In the 2017 - 2018 financial year, $6,130 \mathrm{Kg}$ were harvested from 48 ponds, giving an average of $127.71 \mathrm{Kg}$ per pond, and in the financial year 2018- 2019, 3,867 $\mathrm{Kg}$ of fish was harvested from 53 ponds which is an average of $72.96 \mathrm{Kg}$ per pond (Table 6 ). This was generally a declining trend that was against the projected target of ESP. Table 6 presents a cross-tabulation of the count of ponds harvested vs the number of employees per farm.

Table 7: Count of ponds harvested and number of employees per farm

\begin{tabular}{llllll}
\hline Source of capital & \multicolumn{3}{c}{ Number of employees per farm } & Grand Total \\
\cline { 2 - 5 } & $\mathbf{0}$ & $\mathbf{1}$ & $\mathbf{2}$ & $\mathbf{3}$ & \\
\hline ESP & 2 & 30 & 1 & 1 & $\mathbf{3 4}$ \\
PERSONAL & 0 & 16 & 7 & 2 & $\mathbf{2 5}$ \\
SACCO/GROUP & 0 & 5 & 0 & 0 & $\mathbf{5}$ \\
ESP PERSONAL & 1 & 9 & 1 & 0 & $\mathbf{1 1}$ \\
PERSONAL, SACCO/GROUP & 0 & 1 & 0 & 0 & $\mathbf{1}$ \\
Grand Total & $\mathbf{3}$ & $\mathbf{6 1}$ & $\mathbf{9}$ & $\mathbf{3}$ & $\mathbf{7 6}$ \\
\hline
\end{tabular}

Table 7 indicates that of the 76 farms harvested in the last year three ponds did not have any employees at the farm; 61 ponds were manned by one employee each, 9 ponds manned by 2 employees each and 3 ponds manned by 3 employees. The total number of employees was 88 for the 76 ponds harvested. Close to half of the employees handling the ponds harvested in the last year were funded through ESP. Further interrogation of the respondents showed that the average number of employees per farm is 1.2 earning an average monthly salary of Kshs 3,712.00. Most of the employees on the farms are male youths. ESP had the objective of commercialising the farms to be a source of employment for the youth and women in the rural areas for economic empowerment. Table 8 presents a cross-tabulation of the weight of fish and the number of employees per farm.

Table 8: Weight of fish harvested and number of employees per farm

\begin{tabular}{llllll}
\cline { 1 - 4 } Sum of weight harvested (Kg) & \multicolumn{4}{l}{ Number of employees per farm } & \multicolumn{3}{c}{ Grand Total } \\
\cline { 1 - 5 } Source of capital & $\mathbf{0}$ & $\mathbf{1}$ & $\mathbf{2}$ & $\mathbf{3}$ & \\
\hline ESP & 0 & 4,238 & 35 & 45 & $\mathbf{1 , 3 1 8}$ \\
PERSONAL & 0 & 290 & 822 & 304 & $\mathbf{1 , 5 3 1}$ \\
SACCO/GROUP & 0 & 855 & 0 & 0 & $\mathbf{2 9 0}$ \\
ESP PERSONAL & 100 & 200 & 0 & 0 & $\mathbf{9 5 4}$ \\
PERSONAL, SACCO/GROUP & 0 & $\mathbf{2 , 9 8 8}$ & $\mathbf{8 5 7}$ & $\mathbf{3 4 9}$ & $\mathbf{4 , 2 9 4}$ \\
Grand Total & $\mathbf{1 0 0}$ & $\mathbf{4 8 . 9 8}$ & $\mathbf{9 5 . 2 2}$ & $\mathbf{1 1 6 . 3 3}$ & $\mathbf{5 6 . 5}$ \\
Average weight per pond & $\mathbf{3 3 . 3 3}$ & & & & \\
\hline
\end{tabular}

Table 8 shows the impact of the employees on the farms they work in. The three ponds harvested with no employee assigned recorded an average of 33.33 $\mathrm{Kg}$ of fish per pond. One of the ESP ponds with no employee did not register any harvest. Ponds having a single employee working had an average of 48.98
$\mathrm{Kg}$, which was $69.5 \%$ of the total production, two employees $95.22 \mathrm{Kg}$ and 3 employees $116.33 \mathrm{Kg}$. This implies that the optimum number of employees per pond should be two for maximum return. Table 9 presents Pearson's correlation of the variables discussed in the portions above. 
Table 9: Correlation between farm status, number of ponds, number of pieces, weight harvested and the number of employees.

\begin{tabular}{lcccccc}
\hline & Active & Inactive & $\begin{array}{l}\text { No. of } \\
\text { Ponds }\end{array}$ & $\begin{array}{l}\text { No. of } \\
\text { Pieces }\end{array}$ & $\begin{array}{l}\text { Weight } \\
\text { harvested }\end{array}$ & $\begin{array}{l}\text { No. } \\
\text { employees }\end{array}$ \\
\hline Active & 1.0000 & & & & & \\
Inactive & 0.1204 & 1.0000 & & & & \\
No. of Ponds & 0.5311 & 0.8991 & 1.0000 & & & \\
No. of Pieces & 0.9217 & 0.3972 & 0.7577 & 1.0000 & & \\
Weight harvested & 0.7245 & 0.6625 & 0.9019 & 0.8975 & 1.0000 & \\
No. of employees & 0.7511 & 0.7155 & 0.9360 & 0.9021 & 0.8881 & 1.0000 \\
\hline
\end{tabular}

From Table 9, the following Pearson's correlation coefficients realised to show the following relationships: Active and inactive farms show a weak positive relationship due to the high increase in dropout farmers financed through ESP compared to other sources of finance. However, the active farmers did not show such wide disparity.

Active farms showed a moderate relationship, while inactive farms showed a strong positive relationship with the number of ponds harvested. This leads to a conclusion that a consistent drop in the number of ponds harvested in the last year signifies a high dropout rate of farmers from fish farming.

The number of pieces of fish harvested depends on the activity of the farmers. Therefore, the strong positive relationship between active farms and the number of pieces harvested confirms the trend. The weak positive relationship with inactive farms shows the lack of consistency in the production of the farms before the farmer finally dropped out of farming.

The government of Kenya in 2009 initiated ESP with the aim of commercialising aquaculture. The program aimed to increase the production of farmed fish from 4,000 MT, to over 20,000 MT in the medium term and to more than 100,000 MT in the long term (Charo-Karisa and Gichuhi, 2010). The figures would provide an average production of 95.23 MT per Constituency in the medium term and in the long term 476.19 MT. The study showed harvest of 4,294 Kgs of fish from the Constituency was far short of the expected ESP projected figure in the long term. On interrogation of some of the farm owners, they decried delayed supply of feeds and fertilisers and in some instances against an expectation of $50 \mathrm{Kg}$ bag of fertiliser only $2 \mathrm{Kg}$ was delivered to the farm by the fisheries department. An explanation of the disparity as provided by the department of fisheries was due to a lack of proper facilitation to visit all the farms. Most of the farms where interviews were done indicated that they rarely get visits from the fisheries department. The established farms with high production levels per pond decried lack of support from the fisheries department. The level of production of the ponds is far below the expectations as captured by Munguti et al. (2014) that fish ponds in Kenya range from fro dug holes to designed ponds with inlet and outlet channels and harvest basins yielding approximately 1-2 tons/Ha/year under competent management.

According to KEMRI (2017), the production of farms is affected by a lack of effective group organisation, which reduces the ability to negotiate on the cost of input and share experiences. Best management practices not formally adopted or applied in culture systems, over-reliance on funding from government and development partners creating a 'donor syndrome. This observation is replicated on the ESP program since farmers recruited to manage ponds failed to progress to the first harvest due to a lack of support from the government. Though the funds were availed by the government to ensure full funding of the projects, it is evident to note that some of the funds did not reach the intended farmers. The decline in production levels of the farms evidenced is contrary to Brandler (2007) who stated that aquaculture farming is rising rapidly and by 2030 is estimated that aquaculture production will be close to that of capture production and Dickson et al. (2016) in Egypt aquaculture represented $77 \%$ of total fish production in 2014 compared to $54 \%$ in 2000. 
According to Amadiva and Tarus (2018), aquaculture provides opportunities for employment and income generation to youth and women, especially in rural areas. To this end, ESP had an objective to increase employment opportunities in the fisheries and aquaculture sectors from 80,000 to approximately 2.0 million by 2030 . From the findings, if the optimum number of employees that maximises production per farm is 2 per pond, then 200 ponds per farm should at least have 400 employees. The total count of ponds constructed in Kisumu west constituency total 441 , both active and inactive and therefore, the projected employee number per farm should be 882 employees. Bueno and Pongthanapanic (2014) in their study of the success of aquaculture in Pakistan found out that farm innovation and skilled farm labour reduce costs and raise efficiency. This therefore informs that farmers in the Kisumu West constituency should focus on employing skilled labour to improve pond performance.

The increase in drop out farmers informs on inactive farms directly affect the production levels of the farms, therefore, usurping both the medium-term and long-term objectives of ESP. Therefore, measures should be taken to adequately provide the farmers with the requisite production management skills.

Production directly relates to the number of ponds that are active and strongly related to the active ponds, and if the numbers would increase, then the projected medium-term and long-term values would be attained.

Generally, the weight of fish harvested showed a strong positive relationship to the active ponds, the number of ponds harvested and the number of pieces harvested. This was attributed to the low weight per piece harvested that showed a similar trend. This could be alleviated by engaging the farmers in proper management of the feeding program for the farms to allow the fish to attain the requisite weight.

\section{Production Levels in Fish Pond}

Comparison taken between ESP financed farms and other forms of finance showed that ESP aquaculture farms registered the highest number of farmers dropouts due to low production. Sacco/Group financed projects were the most sustained aquaculture projects.

The production level of farms with ESP as the source of funds were affected by, among others diversion of funds earmarked for the projects. This was exhibited by most of the farmers not receiving all the constituents to be financed as allocated for by the government.

Personal financed farms presented the highest production level in terms of both the number of pieces and the weight of fish harvested. The majority of the farmers financed through ESP raised tilapia, nonetheless still remained the secondhighest in production of catfish in Kisumu West Constituency. The number of employees at a farm played an important role in the realisation of higher production at the aquaculture farms. Nevertheless, most of the ESP-financed farms did not employ skilled employees to patronage in the daily farm activities. Labour was only sourced during harvest and pond construction.

\section{CONCLUSION}

Management is the cornerstone of a sustainable business enterprise. Acquisition of production management skills was therefore fundamental in the realisation of commercialised aquaculture as envisaged by the establishment of ESP.

Averagely more than half of the farmers were trained on technical and post-harvest skills at the initiation point of the projects. Technical and postharvest management skills that include predator identification and management, early fish disease detection, fish feeding program, record keeping, pricing of fish, storage and value addition showed a significant relationship with the performance of the aquaculture farms. Therefore, training and capacity building should be enhanced in these areas to turn around the sector and achieve the objective of commercialised farms.

Post-harvest management skills should be well planned for in advance to achieve competitive pricing of the fish products. Proper record-keeping, ability to raise funds to restock the farms, competitive pricing of the fish products and value addition are core factors to the sustainable performance of the farms. Therefore, these skills 
should be continuously imparted to the farmers through the synergy of the available stakeholders with the County Government taking a lead role.

Based on the findings and discussions, if farmers managed aquaculture as business enterprises, it could afford employment opportunities and source of income for both youth and women in the rural areas. Both the National and County Governments can revamp the ESP established projects by ensuring the farmers are clustered regionally into smallholder groups to facilitate ease of training and visit by extension officers. The groups can act as a suitable avenue for marketing and value addition of the fish products. The production management skills if accurately implemented, then ESP-funded aquaculture will accomplish the core objective of the improved economic status of the rural-based entrepreneurs and consequently the country's economic growth.

\section{RECOMMENDATIONS}

Clear guidelines on recruitment criteria should be set for future funding by the County and/or National Government or Non-Governmental institutions to mitigate -dependency on donor funds and establish sustainable projects. This will also serve to alleviate the discrepancies evidenced during the financing of ESP projects. A robust project coordination and management team should be established with production targets to achieve within a given time frame from the financed farms.

Development of aquaculture best production management practice and farmer training program that should be implemented across the Constituency to provide consistent information delivery and continuous feedback mechanism. To satisfactorily reach many farmers and deliver modest training, an inter-sector approach should be adopted to increase synergy. Kisumu West Constituencies hosts Maseno University, Maseno Veterinary Farm, Maseno Farmers Training Centre, Ramogi Institute of Advanced Technology, all with facilities and expertise in training on enterprise management. The department of fisheries if not well resourced in the form of manpower should professionally engage other institutions for support in training and delivery of refresher courses on production management skills to both extension officers and the
farmers.Formation of Sacco's or groups based on the region of operation. This will enhance access to farmers through training, encourage peer learning and enhance returns through pooling to sell. Through the groups, the farmers can develop marketing and training information systems (mobile app) this will provide linkages with the value chain stakeholders with the intent to maximise profit margins and management information sharing.

\section{REFERENCES}

Amadiva, J. M. \& Tarus, V. (2018). Aquaculture industry in Kenya. Nairobi, Kenya: Ministry of Agriculture, Livestock, Fisheries and Irrigation.

Bhattacherjee, A. (2012). Social science research: Principles, methods, and practices. Textbooks Collection. http://scholarcommons.usf.edu/oa_textbooks/3.

Brander, K. M. (2007). Global fish production and climate change. PNAS, 104 (50), 19709 - 19714,

Brummet, R.E. \& Noble, R. (1995). Aquaculture for African smallholders. ICLARM Technical Report 46, Manila, PH: ICLARM.

Bueno, P. B. \& Pongthanapanich, T. (2014). Success factors in aquaculture enterprises in the Pacific: Farm assets and farm performance of private aquaculture enterprises, a case study. Food and Agriculture Organization of the United Nations.

Charo- Karisa, H. \& Gichuhi, M. (2010). End of year report fish farming enterprise productivity program phase 1: Aquaculture development working group. Ministry of Fisheries Development Nairobi, KE, Overview of the Fish Farming Enterprise Productivity Program.

Dickson, M., Nasr-Allah, A., Kenawy, D. \& Kruijssen, F. (2016). Increasing fish farm profitability through aquaculture best management practice training in Egypt. International Journal on Aquaculture, 465 (2016), $172-178$.

Edwards, P. (2002). Aquaculture, poverty impacts and livelihoods. Natural Resource Perspectives, 2000 (56), 1-4. 
FAO. (2012). Anti-hunger program reducing hunger through agricultural and rural development and wider access to food. Rome: Author.

FAO. (2018). The state of world fisheries and aquaculture 2018: Meeting the sustainable development goals. Rome: Author.

KMFRI (2017). Kenya Aquaculture Brief 2017. Retrieved August 12, 2018, from http://www.kmfri.co.ke/images/PDF/kenyaaquaculture_Brief_2017.pdf.

Munguti, J. M., Kim, J. \& Ogello, E. O. (2014). An overview of Kenyan aquaculture: Current status, challenges and opportunities for future development. International Journal Fisheries and Aquatic Sciences, 17(1), 1-11.

Muir, J. \& Allison, E. (2007). The threat to fisheries and aquaculture from climate change. Penang, Malaysia: The World Fish Centre.

Mwatsuma, M. K., Cherutich, B. K. \& Nyamu, H. M. (2012). Performance of commercial aquaculture under the Economic Stimulus Program in Kenya. International Journal for Business and Commerce, 2 (3), 01-20.

Opiyo, M. A., Marijani, E., Muendo, P., Odede, R., Leschen, W., \& Charo-Karisa, H. (2018). A review of aquaculture production and health management practices of farmed fish in Kenya. International Journal of Veterinary Science and Medicine, 6(2), 141-148. 